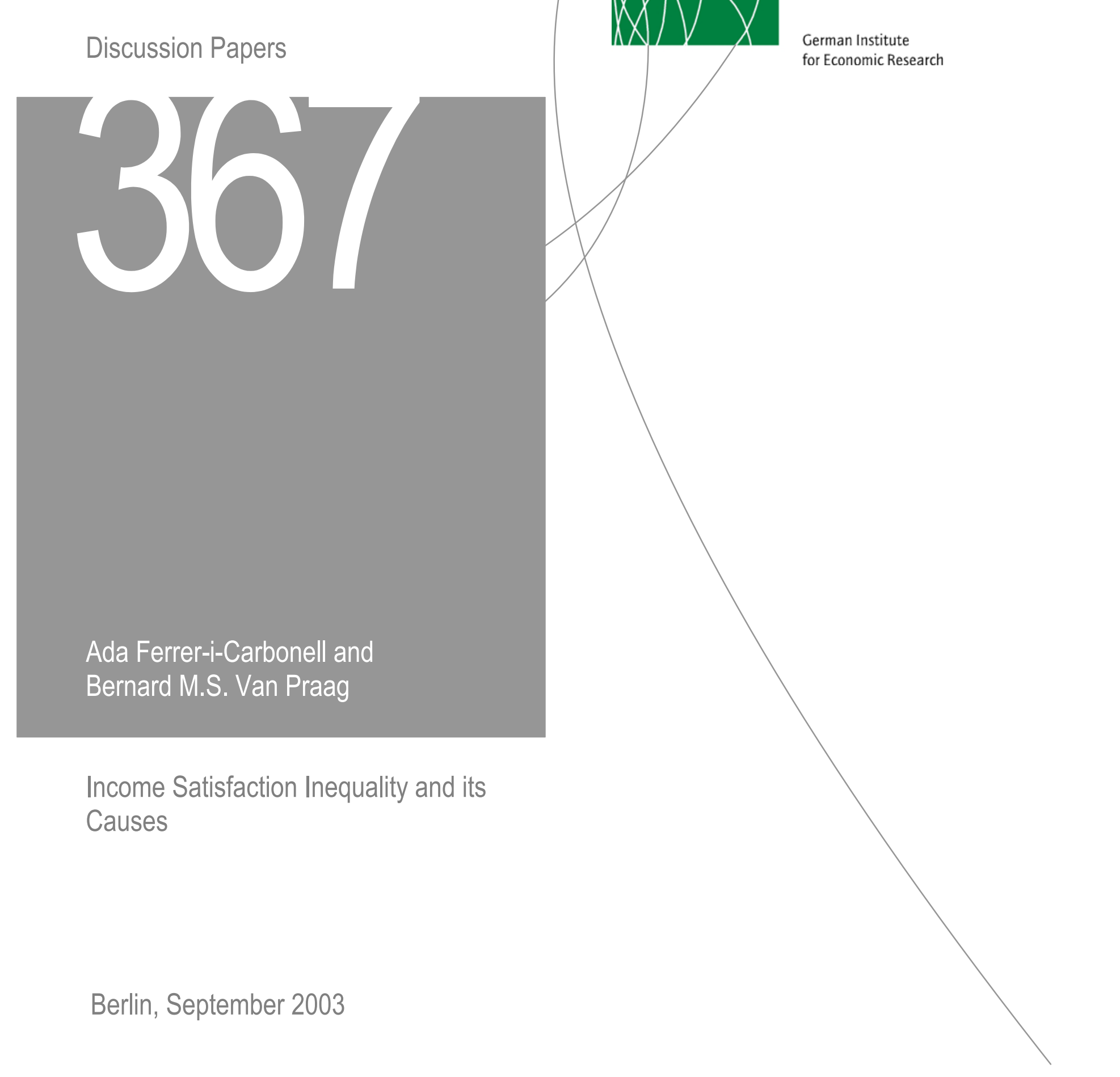


Opinions expressed in this paper are those of the author and do not necessarily reflect views of the Institute.

DIW Berlin

German Institute

for Economic Research

Königin-Luise-Str. 5

14195 Berlin,

Germany

Phone +49-30-897 89-0

Fax $\quad+49-30-89789-200$

www.diw.de

ISSN 1619-4535 


\title{
Income Satisfaction Inequality and its Causes
}

\author{
Ada Ferrer-i-Carbonell ${ }^{\mathrm{a}}$ and Bernard M.S. Van Praag ${ }^{\mathrm{b}}$

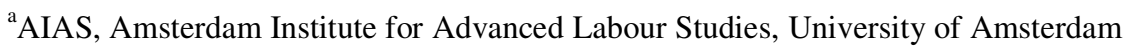 \\ aferrer@fee.uva.nl \\ ${ }^{\mathrm{b}}$ Faculty of Economics and Econometrics, University of Amsterdam \\ and Tinbergen Institute \\ B.M.S.vanPraag@uva.nl
}

\begin{abstract}
In this paper, the concept of Income Satisfaction Inequality is operationalized on the basis of individual responses to an Income Satisfaction question posed in the German Socio-Economic Panel (GSOEP). Income satisfaction is the subjective analogue of the objective income concept and includes objective income inequality as a special case. The paper introduces a method to decompose Income Satisfaction Inequality according to the contributions from variables such as income, education, and the number of children. Given the panel structure of the data, inequality may be attributed partly to permanent individual circumstances and partly to transitory changes. The paper shows that by far the largest part of the satisfaction inequality has to be ascribed to unobserved heterogeneity. Distinguishing between a structural and an unexplained part of inequality we find that income explains the largest part of structural Income Satisfaction Inequality together with household membership; for non-working individuals, the age distribution is very relevant as well.
\end{abstract}

Keywords: Equivalent Income, Financial Satisfaction, Income Satisfaction, Income Inequality, Variance Decomposition.

JEL Classification: D63, I32.

Acknowledgments: The authors would like to thank Peter Hop and Adam Booij for their help and comments. The usual disclaimers apply.

August 1, 2003 


\section{Introduction}

Since Gini (1912) and Dalton (1920), the distribution and inequality of income has been an important subject of study for economic and social scientists. Recent surveys are offered in the handbooks edited by Atkinson and Bourguignon (1999) and Silber (1999). The study of income inequality entails two main issues (see Cowell (1999)). First, the income concept has to be operationalized and measured. Second, a definition of inequality has to be agreed upon and consequently an index of inequality, namely a measure of the dispersion of income or welfare, has to be chosen.

The basic question underneath is why we are so interested in income inequality. It is not just an administrative statistic. The reason is that income or 'equivalent income' is taken as a proxy for welfare. It follows that income inequality is seen as synonymous to welfare inequality, a performance index of society. The literature bears witness that there is no generally accepted measure of welfare. This is caused among other reasons by uneasiness about whether income in itself is a suitable measure of welfare. This is especially true for modern welfare states where a considerable part of our consumption is provided by the state and not through the market. Additionally, income has to be corrected for individual and household characteristics if it aims at measuring welfare. For example, it is evident that two households with the same income but different family sizes $f_{s}$ will need different incomes to be equally satisfied. Hence, income $y$ should be 'corrected' for family size, which would lead to what is known as 'equivalent income' $\tilde{y}$. For instance, if we apply the correction factor $g(f s)$ equivalent income becomes $\tilde{y}=y \cdot g(f s)$. In order to compare incomes and to get some idea about income inequality, it does not make much sense to define income inequality on nominal income. Inequality should be measured with respect to equivalent incomes. It is evident that this will change income inequality. For instance, if we use the variance of log-incomes as inequality measure, we have

$$
\operatorname{var}(\ln (\tilde{y}))=\operatorname{var}(\ln (y))+\operatorname{var}\left(\ln (g(f s))+2 \operatorname{cov}\left(\ln (y), \ln \left(g\left(f_{s}\right)\right)\right)\right.
$$

This shows that the inequality of equivalent incomes, as defined by the log-variance, will differ from the inequality of nominal incomes. One may be larger or smaller than 
the other. It is evident that there are more intervening variables than family size. Say, we have a vector $x$ of such variables. Then the definition of equivalent income may be straightforwardly generalized to correct for $x$. The problem is the definition and empirical operationalization of the correction factor $g(x)$. Our definition will be simple. If two individuals $A$ and $B$ report to be equally satisfied with their incomes $y_{A}$ and $y_{B}$, we assume those two incomes to be equivalent. This implies that if we take $A$ as the reference then $g(x)=y_{B} / y_{A}$. In practice, this factor is derived by looking at 'income satisfaction questions', which are now posed as a matter of routine in socioeconomic surveys. It may also be that $x$ includes some unobservable individual characteristics $\varepsilon$. Then exact correction at the individual level will be impossible. However, we can still operationalize for those variables that are observable.

In this paper, we try a new approach to assess inequality by not looking at nominal income as our basic variable but at the satisfaction derived from income. We call this income satisfaction and we measure it by means of individual answers to an income satisfaction question. We believe that this empirical approach leads to a welfare inequality concept, which does more right to our intuitive feelings about inequality than the measures that account for income differences only.

It is possible to define and measure an index for income satisfaction. The income satisfaction concept used in this paper does implicitly incorporate the necessary corrections. Income satisfaction is empirically defined through the analysis of individual responses to an income satisfaction question. The paper aims at explaining the individual's income satisfaction by objective variables $x$, such as income, education, and number of individuals in the household. We denote that satisfaction by $f(y ; x, \theta)$, where $\mathrm{y}$ stands for nominal income, $\mathrm{x}$ for other individual circumstances, and $\theta$ for a vector of parameters to be estimated. If there holds $f(y ; x, \theta) \equiv y$, the subjective perception will coincide with nominal income. Hence, usual income inequality is embedded in the income satisfaction inequality concept as a special case.

The income satisfaction inequality $\left(I_{\text {sat }}\right)$ is here measured in such a way that if satisfaction would coincide with income, that is $f(y ; x, \theta) \equiv y$, then $\left(I_{s a t}\right)$ would equal the variance of log-incomes. The variance of the logarithm is one of the most frequently used measures of inequality, together with the relative mean deviation, the 
variance, the coefficient of variation, the Atkinson index, the Gini coefficient, and Theil's entropy measure (see Atkinson, 1970; Sen, 1973). All those inequality measures are functions of moments of the income distribution. It is well known that the distribution of personal and household incomes is rather well -approximated by a log- normal distribution. When the income distribution is (approximately) log-normal $\Lambda\left(\mu, \sigma^{2}\right)$, all income inequality indexes are (approximately) functions of the two distribution parameters. The parameter $\mu$ gives the position of the distribution, while $\sigma^{2}$ is a measure for the relative income differences. The log-variance $\left(\sigma^{2}\right)$ as a measure of inequality has the advantage that it does not depend on the money unit. Other measures are simple functions of $\sigma^{2}$ and $\mu$. Theil (1967, chapter 4; 1979) shows that the Theil Entropy measure equals $(1 / 2) \sigma^{2}$ in the case of log-normality. Van Praag (1978) derived a similar result for the Atkinson index, and Aitchison and Brown (1960) for the Gini index. If approximate log-normality holds, there is not much to be gained by considering more indices simultaneously, given the one-to-one relationship between such indexes. Thus we will exclusively focus on the variance of the logarithm. This choice is clearly a subjective one but this index is very useful when looking at the causes of inequality. It is obvious that we may apply to the income satisfaction $f(y ; x, \theta)$ any inequality index that may be applied to nominal income $y$. This holds for the Atkinson index and the related social welfare function (SWF-) approaches. Let the SWF be defined as $\sum_{n} h\left(f\left(y_{n}, x_{n} ; \theta\right)\right)$, where $h($.$) stands$ for the contribution to the SWF of an individual with individual satisfaction $f$. Then the SWF-maximizing situation is found by maximizing the SWF under the constraint $\sum_{n} y_{n}=Y$, where $Y$ stands for (fixed) national income. Under general circumstances this optimum will be reached if individual satisfactions (not incomes!) are equal.

The paper focuses on the study of the causes of income satisfaction inequality $\left(I_{s a t}\right)$. This is equivalent to examining which objective variables contribute most to the existing income satisfaction variance. Since individual income satisfaction can be partly explained by differences in income, the number of children, age, and education, income satisfaction inequality can be decomposed along the same lines. Thus, $I_{s a t}$ is, to a certain extent, explained by the underlying inequalities in those objective 
variables. If we have longitudinal data, income satisfaction inequality can be further decomposed according to individual permanent differences in objective factors and individual transitory changes. Finally, income satisfaction inequality can also be decomposed into within-and between-group inequalities. We consider the inequality between East and West Germany and between the groups of workers and nonworkers.

The novel contribution to the literature of the present approach to measure income satisfaction inequality is threefold. First, if individual satisfaction with own income is not only caused by income, but is also dependent on other individual characteristics, such as age and family size, the income satisfaction concept implicitly includes the corrections required to make individual welfare equivalent and comparable. Second, the empirical estimation of income satisfaction allows for testing different specifications of the relationship between income and income satisfaction. As income inequality has not to be seen as an administrative index but as an index of the inequality in income satisfactions, we need the best possible specification of that relation between income and income satisfaction. Third, as we know the causes of income satisfaction, we may also view satisfaction inequality as caused by inequalities with respect to the underlying variables like income, age, household size, and so on.

This paper is organized as follows. Section 2 introduces the data and the income satisfaction question. Section 3 presents the estimation results for the income satisfaction question. Section 4 discusses the income satisfaction inequality concept, the decomposition method, and presents the empirical findings on the causes of inequality. Section 5 concludes.

\section{Income satisfaction}

The empirical analysis is based on the German Socio-Economic Panel (GSOEP) data. The GSOEP is a longitudinal household panel that started in the Federal Republic of Germany in 1984. After the reunification of Germany, (former) East-German households have been included (see Wagner et. al, 1993). This paper is based on the waves 1992 to 1997, including more than 20,000 individuals of which about 30\% are Eastern individuals. It is well-known that the two parts of the country have lived since 1945 under different regimes with respect to opportunities, fiscal and social security 
regulations, the supply of public goods and housing, and last but not least political philosophy. Although the populations are converging since the reunification of the two German states, we think it still prudent to handle them as different sub-samples for the period 1992-7. Further, the sample is divided between workers and nonworkers, as we assume that the significance of income will differ between workers and non-workers. For workers the income concept will have two significances. The first one is that of income as a source of material well-being. The second meaning is derived from the fact that the income level is strongly correlated with how your work contribution is evaluated by the employer and the social environment. For individuals, who live from pensions, social benefits or alimonies the second meaning of income is not or hardly relevant. Each group will also refer itself to a different reference group. It is known that many people without a proper job environment feel rather isolated from what is going on in society at large. The set of non- workers is somewhat heterogeneous, since it includes unemployed workers, housewives, who have no intention to participate in the labor force and retired individuals. More precisely, the Western group consists of $65 \%$ women, $23 \%$ men younger than 65 and $12 \%$ males older than 65. For the Eastern non-working population the corresponding figures are $62 \%, 28 \%$ and $10 \%$.

From table 2 we will see whether these distinctions are empirically justified. Since the numbers of individuals who switch from East to West, or from 'nonworking' to 'working', and vice versa are very small, they are treated as new respondents in the new group (see Hunt, 1999, 2000; Pannenberg, 1997).

The Income Satisfaction (IS)- question is asked to all respondents of the GSOEP. Satisfaction questions have appeared in questionnaires for over more than three decades starting with Cantril (1965) and Likert (1932). The Income Satisfaction question in the GSOEP that is used in this paper runs as follows

'How satisfied are you today with the following areas of your life?

(Please answer by using the following scale, in which 0 means totally unhappy and 10 means totally happy)

How satisfied are you with your household income 
The answer to this question is termed the individual's Income Satisfaction (IS) level. In this module the discrete answers vary from 0 to 10 , where 0 stands for 'totally unhappy' and 10 for 'totally happy'. Satisfaction questions have been amply used by economists, psychologists, and sociologists. Economists have used answers to satisfaction questions as a proxy measure of the individual's welfare in order to study individual preferences, behavior, welfare, and poverty (see, for example, Clark and Oswald (1994), Frey and Stutzer (2002), Plug, Van Praag, Krause and Wagner (1997), DiTella et al., 2001; Easterlin, 2000; Ferrer-i-Carbonell and Van Praag, 2001; Frijters, 2000; Frey and Stutzer, 2000; Ng, 1997; Van Praag, 1971; Van Praag et al., 2001).

In order for $I S$ questions to be meaningful, one needs to assume that respondents are able to understand and to answer subjective questions and that they evaluate and respond to such questions in a similar manner, such that individual answers can be compared. This does not necessarily imply that individuals who grade their satisfaction at 8 are twice as satisfied as those who grade their satisfaction by 4 . Interpersonal comparability does not imply a cardinal interpretation per se. The literature on subjective well-being, which is large and growing (for an overview see Kahneman et al. 1999 and Diener et al., 1999) shows clear consistencies across studies. This may be interpreted as empirical evidence of the meaningfulness of questions on satisfaction and of the capacity and willingness of individuals to respond to such questions. The assumption of interpersonal comparability has been long discussed in the literature (see, for example, Sen, 1999 and Van Praag, 1991). In this paper, we start from the working hypothesis that individual answers to satisfaction questions are (ordinally) comparable among individuals. Thus, it is assumed that two individuals, answering a ' 5 ', experience the same level of income satisfaction, although their material circumstances may differ. Notwithstanding the fact that there is a vast amount of literature, which either implicitly or explicitly starts from this comparability assumption, it is impossible to provide direct evidence that this assumption is warranted. That would require the existence of a basic and generally accepted method of direct (e.g. physical) satisfaction measurement, but such a method does not exist (yet). If we ask other questions we find indeed that one question is correlated with or predicts the results of another instrument quite well. Obviously, but this is a technical aspect, in practice comparability is always approximate, as the discrete scaling implies a rounding-off error for each response. 
Objective variables are not the only determinants of individual satisfaction. Personal traits, such as extroversion, optimism, or capacity to adapt to adverse situations, are also important determinants of individual's welfare. In fact, it is argued that only about 8 to $20 \%$ of individual life satisfaction, which is an even broader concept than income satisfaction, is explained by objectively measurable variables (Argyle, 1999; Diener et al., 1999; Kahneman et al., 1999). It is also important to bear in mind that the individual is subject to adaptation phenomena and the relative income hypothesis. Adaptation theory suggests that individuals adapt their satisfaction norms to new situations (Helson, 1964). This phenomenon is called 'the hedonic treadmill' by Brickman and Campbell (1971), while Van Praag (1971) coined it 'preference drift'. The relative income hypothesis says that the individual's satisfaction with income depends on how its income compares to that of others (Kapteyn and Van Herwaarden, 1980, Clark and Oswald (1996), Ferrer-i-Carbonell, 2002)). Thus, changes in one's income or in the income distribution of a society will not necessarily be reflected into changes in income satisfaction. This has an ethical dimension that is not further discussed in this paper.

Table 1 presents the distribution frequencies of $I S$ in the total sample. We see that the bulk of the population is found in the classes 4 to 8 , but there are also a substantial number of observations in the extremes. It is especially remarkable that only about $0.5 \%$ of the respondents evaluate their own financial situation by zero. We see that the average difference in satisfaction between Western workers and nonworkers is not large, but that the difference between the Western and Eastern part of the country is much larger. The same pattern is found when we look at Table 1b., in which we tabulated the satisfactions, differentiated according to income quartiles. Table 1b shows that IS is on average larger, the richer an individual is. This holds within the sub-samples. For example, the richer $6 \%$ of West workers have, in average, a IS of almost 8 , while the poorest $25 \%$ of the sample have a satisfaction level of 6.6. 
Table 1.a Frequency distributions and averages of Income Satisfaction (IS), GSOEP 1992-1997

\begin{tabular}{lcccc}
\hline IS & $\begin{array}{c}\text { West } \\
\text { Workers }\end{array}$ & East Workers & $\begin{array}{c}\text { West Non- } \\
\text { Workers }\end{array}$ & $\begin{array}{c}\text { East Non- } \\
\text { Workers }\end{array}$ \\
\hline 0 & $0.56 \%$ & $0.59 \%$ & $0.78 \%$ & $1.33 \%$ \\
1 & $0.49 \%$ & $0.52 \%$ & $0.81 \%$ & $1.24 \%$ \\
2 & $1.16 \%$ & $2.16 \%$ & $1.94 \%$ & $3.12 \%$ \\
3 & $2.48 \%$ & $4.21 \%$ & $3.65 \%$ & $6.28 \%$ \\
4 & $4.05 \%$ & $6.15 \%$ & $4.48 \%$ & $7.74 \%$ \\
5 & $10.90 \%$ & $18.02 \%$ & $12.29 \%$ & $19.29 \%$ \\
6 & $11.42 \%$ & $16.62 \%$ & $10.39 \%$ & $13.86 \%$ \\
7 & $20.75 \%$ & $23.25 \%$ & $17.80 \%$ & $17.07 \%$ \\
8 & $27.41 \%$ & $20.28 \%$ & $24.67 \%$ & $19.44 \%$ \\
9 & $12.67 \%$ & $5.70 \%$ & $12.04 \%$ & $6.22 \%$ \\
10 & $8.11 \%$ & $2.51 \%$ & $11.14 \%$ & $4.41 \%$ \\
\cline { 1 - 4 } Average & 7.092 & 6.332 & 6.992 & 6.120 \\
\hline Total & 30539 & 11360 & 20611 & 8501 \\
observations & & & & \\
\hline
\end{tabular}

Table 1.b Averages of Income Satisfaction (IS) per income percentile ${ }^{1}$, GSOEP 1992-1997

\begin{tabular}{rcccc}
\hline & Lowest 25\% & Lowest 50\% & Lowest 75\% & Top 6\% \\
\hline West Workers & & & & \\
Average Income & 3011 & 4105 & 5432 & 12088 \\
Average IS & 6.633 & 6.989 & 7.224 & 7.976 \\
East Workers & & & & \\
Average Income & 2697 & 3463 & 4188 & 8955 \\
Average IS & 5.769 & 6.202 & 6.366 & 7.693 \\
West Non-Workers & & & & \\
Average Income & 2276 & 3294 & 4675 & 10938 \\
Average IS & 6.384 & 6.876 & 7.214 & 7.898 \\
East Non-Workers & & & & \\
Average Income & 1808 & 2566 & 3463 & 7332 \\
Average IS & 5.598 & 6.006 & 6.387 & 7.448 \\
\hline
\end{tabular}

\section{Estimation}

Satisfaction questions are usually explained by means of latent variable models because $I S$ is an ordered categorical variable. In our case it takes the values $0,1, \ldots$, 10. We assume the usual Ordered Probit model. The real axis is partitioned in intervals $\left(-\infty, \mu_{0}\right] \ldots,\left(\mu_{10}, \infty\right)$, such that the latent variable $I S^{*} \in\left(\mu_{i}, \mu_{i+1}\right]$ if $I S=\mathrm{i}$.

We assume that the latent variable IS* obeys the equation

\footnotetext{
${ }^{1}$ Due to rounding off the brackets contain approximately $25 \%$.
} 


$$
\operatorname{Ln}\left(I S_{n t}^{*}\right)=C_{t}+\alpha_{y} y_{n t}+\alpha_{z} Z_{n t}+\alpha_{x} X_{n t}+\beta_{y} \bar{y}_{n}+\beta_{x} \bar{X}_{n}+\varepsilon_{n t}+v_{n}
$$

where $\mathrm{n}$ stands for the individual and $\mathrm{t}$ for time. The explanatory variables are divided into two groups, i.e. $X$ and $Z$. The first are included in the regression in two forms: at the yearly value, $X_{n t}$, and as the average of $X_{n}$ across time $t\left(\bar{X}_{n}\right)$. The vector $X_{n t}$ includes number of children and adults in the household. The vector of explanatory variables $Z$ are only included at their yearly value $\left(Z_{n t}\right)$. As Equation (2) shows, income is included both at its yearly value and as an average across the 6 years period.

Income satisfaction is assumed to depend on individual and household objective characteristics. Next, the specification is discussed (see also van Praag et al., 2003). We assume that satisfaction depends on log-household income $y$, and the number of individuals to be supported, where we distinguish between children (below 16) and adults. As we assume that the number of children will have a negative effect on income satisfaction, but that this effect will be less negative, the higher the household income, we introduce an interaction term between income and children as well. Age is included as $\log$ and $\log$-square, because it is frequently found that satisfaction, not only with income but also with the job, has a U-shape effect on satisfaction. It implies that as we grow older our needs increase. We become less satisfied with income if it stays the same over time. This has to do with adaptation and with the fact that most members of our reference group will enjoy income growth over time. Due to the squared term the effect reaches a minimum about fifty; after that age the effect reduces. A similar effect with respect to job satisfaction was found by Clark and Oswald. We assume that living together will have a positive scale effect, as household chores can be divided over two and there are substantial economies of scale when living together. On the other hand a family with two breadwinners has less time available for household production than a traditional household, which is still frequently found in Germany 1997. Hence, we assume that a two-breadwinner family will be less satisfied than a one-breadwinner family with the same household income. Finally, we include time dummies, representing inflation and general 'rising expectations' and a gender dummy, which equals one for a male respondent and zero for a female respondent. 
As discussed above, some of the explanatory variables are included in two ways, viz. as their mean value and at their annual values. We do this because we expect that changes in the $X$-variables will not immediately affect income satisfaction to the full extent, but that there will be an adaptation process to new circumstances. The coefficient of the long-term average $\bar{X}_{n}$ stands for the effect of a permanent change, while the coefficient of $X_{n t}-\bar{X}_{n}$ stands for the immediate short-term effect of a change. For statistical reasons this specification was advocated by Mundlak (1978). He interpreted the $\bar{X}_{n}$ as picking up the correlation between observed individual characteristics and the individual unobserved effects. In this way, Mundlak aimed at ensuring orthogonality between $X$ and $v$.

Equation (1) can be rewritten as

$\operatorname{Ln}\left(I S_{n t}^{*}\right)=C_{t}+\alpha_{y}\left(y_{n t}-\bar{y}_{n}\right)+\alpha_{x}\left(X_{n t}-\bar{X}_{n}\right)+\left(\alpha_{y}+\beta_{y}\right) \bar{y}_{n}+\left(\alpha_{x}+\beta_{x}\right) \bar{X}_{n}+\alpha_{z} Z_{n t}+\varepsilon_{n t}+v_{n}$

In equation (2) we distinguish for the $X$-variables a transitory and a permanent effect. The permanent effect is $(\alpha+\beta)$, and the transitory effect is $\alpha$. For some variables, the permanent effects have a clear interpretation. For example, the effect of mean income is the permanent income effect (Friedman, 1957).

As we assume a considerable correlation between annual errors, we model the error as $\varepsilon_{n t}+v_{n}$. The individual random effect $v_{n}$ and the error term $\varepsilon_{n t}$ are assumed to be normally distributed and to be correlated neither with each other nor with the explanatory variables $X$ and $Z$. The total residual variance equals $\sigma^{2}(v)+\sigma^{2}(\varepsilon)$. The individual random effect, which varies over individuals $n$ but which is time-constant per individual, may be interpreted as standing for those individual psychological traits that are not observed in the data set (unobserved heterogeneity). We notice that in the literature of the evolution of wages over time some more complex error structures are implemented (see Lillard and Willis (1978), Baker (1997), Dickens (2000)). These interesting ideas seem to be outside the scope of this introductory paper, which focuses on the new satisfaction inequality concept. 
It is well known that identification in the Probit model is only possible by addition of a normalizing condition, for which we traditionally take $\sigma^{2}(\varepsilon)=1$. If we would impose $\sigma^{2}(\varepsilon)=2$, we would have to multiply all effects by $\sqrt{2}$. It is easy to see that the $t$-values under both specifications will be the same. However, we may impose other identifying conditions like setting one of the non-zero effects equal to one. Say, under the standard-normalization the effect was $\alpha$, then under the new normalization all coefficients would have been multiplied by $\alpha^{-1}$ while the error variance would be multiplied by $\alpha^{-2}$. Hence, one can use standard-software and change the identifying condition after estimation. This indeterminacy implies that the value of the income satisfaction inequality index, which we are about to define, depends on the specific normalization chosen. In order to make the satisfaction index simultaneously comparable between different samples and with the variance of logincomes, we re-normalize by multiplying the Probit-estimates with the factor $1 /\left(\alpha_{y}+\beta_{y}\right)$. For the variances used in the following tables this implies a multiplication by $\left(\alpha_{y}+\beta_{y}\right)^{-2}$. By applying this normalization we ensure that the structural parts of income satisfaction estimated with different error variances, may be compared with each other.

Table 2 presents the estimation results for equation (1) as estimated by an Ordered Probit model with individual random effects. Table 2 shows that we allowed for the inclusion of a permanent effect and a transitory effect for three variables, i.e. income, number of children in the household, and number of adults. The income ${ }^{2}$ effects are all positive and significant. Hence, normalization by division through the sum of both effects is a valid operation. The transitory income effect for WestGerman workers equals 0.261. For Western non-workers, the effect is of the same order. For Eastern workers and non-workers the transitory income coefficients are much larger. The income effect also depends on the number of children via the interaction term income-children. This interaction term has a slight mitigating effect on the cost of children for Westerners, but it is non-significant for Easterners.

\footnotetext{
${ }^{2}$ Income is the answer to the following question: "If everything is taken together: How high is the total monthly income of all the household members at present? Please give the net monthly amount, in other words after the deduction of tax and national insurance contributions. Regular payments such as rent subsidy, child benefit, government grants, subsistence allowances, etc., should be included. If not known exactly, please estimate the monthly amount”. (answers are in German Marks).
} 
The age coefficients are all significant, where $\operatorname{Ln}\left(I S^{*}\right)$ has a U-shape with respect to age. Western workers reach a minimum income satisfaction at the age of 44 and Eastern workers at 56. For non-workers, income satisfaction attains its minimum at around 37. Apart from psychological developments over human life there may be more mundane reasons: households needs increase with the number of children and spending on consumer durables and housing is more important in the first half of the life cycle. Later in life children are leaving the household and investments in housing and furniture have been completed. Another reason for this fall in satisfaction during the first period in life may be that individuals get used their material status and take it as a matter of course. The education effect is positive in the West, non-significant for Eastern workers, and negative for Eastern non-workers. The effect of more education is ambiguous. On one hand more education leads to more efficient consumption. This would point to a positive effect on income satisfaction. We find this effect for WestGerman citizens. On the other hand more education widens your horizon and will increase someone's expectations. This would yield a negative effect. The education effect is a mixed product. For East-Germany we find that both factors cancel out for workers, while the widening horizon-effect has the upper hand for East-German nonworkers. The presence of more adults or children has a negative effect on income satisfaction for all four sub-samples. If one lives together with a partner in one household, this increases individual income satisfaction. Male respondents are less content than females. The estimation results show that this coefficient is nonsignificant. The individual random effect, i.e. individual unmeasured psychological characteristics, explains between 30 and $40 \%$ of the total unexplained variance, being somewhat higher for Westerners than for Easterners.

We notice that the equation differences between sub-samples show that it is indeed justified to estimate the model for the four sub-samples separately. 
Table 2. Income Satisfaction (IS) Regression.

Ordered Probit with individual random effects, GSOEP 1992-1997

\begin{tabular}{|c|c|c|c|c|c|c|c|c|}
\hline & \multicolumn{2}{|c|}{ West Workers } & \multicolumn{2}{|c|}{ East Workers } & \multicolumn{2}{|c|}{ West Non-Workers } & \multicolumn{2}{|c|}{ East Non-Workers } \\
\hline & Estim. & Est/StErr & Estim. & Est/StErr & Estim. & Est/StErr & Estim. & Est/StErr \\
\hline Constant & 5.427 & 3.461 & 3.660 & 1.954 & 16.445 & 13.431 & 19.997 & 10.647 \\
\hline Dummy for 1992 & 0.416 & 12.422 & -0.079 & -2.054 & 0.141 & 3.664 & -0.359 & -5.521 \\
\hline Dummy for 1993 & 0.425 & 12.168 & 0.174 & 4.303 & 0.384 & 9.791 & -0.064 & -1.076 \\
\hline Dummy for 1994 & 0.346 & 11.362 & -0.288 & -7.822 & 0.491 & 14.820 & 0.098 & 1.892 \\
\hline Dummy for 1995 & 0.300 & 8.582 & 0.115 & 2.861 & 0.387 & 10.060 & 0.141 & 2.199 \\
\hline Dummy for 1996 & 0.412 & 11.157 & 0.226 & 5.456 & 0.351 & 8.805 & 0.170 & 2.627 \\
\hline Ln(age) & -5.354 & -5.981 & -4.223 & -3.915 & -11.861 & -17.887 & -12.863 & -12.779 \\
\hline $\operatorname{Ln}(\text { age })^{\wedge} 2$ & 0.707 & 5.614 & 0.529 & 3.442 & 1.641 & 18.114 & 1.767 & 12.847 \\
\hline Minimum age reached at & 43.993 & & 54.310 & & 37.101 & & 38.053 & \\
\hline Ln(net family income) & 0.261 & 7.139 & 0.422 & 8.710 & 0.240 & 6.023 & 0.427 & 5.786 \\
\hline $\operatorname{Ln}$ (years of education) & 0.258 & 3.334 & 0.009 & 0.090 & 0.260 & 2.943 & -0.325 & -2.588 \\
\hline Ln(number of adults) & -0.176 & -4.735 & -0.247 & -4.651 & -0.041 & -0.848 & -0.152 & -1.600 \\
\hline $\operatorname{Ln}($ number of children +1$)$ & -0.727 & -1.973 & -0.408 & -0.839 & -0.778 & -2.197 & -0.817 & -1.140 \\
\hline $\begin{array}{l}\operatorname{Ln}(\text { net family income }) \\
* \operatorname{Ln}(\text { child. }+1)\end{array}$ & 0.077 & 1.732 & 0.024 & 0.394 & 0.079 & 1.819 & 0.082 & 0.919 \\
\hline Male & -0.040 & -1.319 & -0.073 & -2.212 & -0.257 & -7.392 & -0.134 & -2.794 \\
\hline Living together & 0.211 & 5.860 & 0.216 & 3.969 & 0.259 & 8.393 & 0.100 & 1.743 \\
\hline Two Earners & -0.032 & -0.964 & -0.083 & -1.835 & $X X X$ & & $X X X$ & \\
\hline Mean (Ln(net family inc.) & 0.739 & 13.716 & 0.578 & 8.666 & 0.760 & 13.659 & 0.573 & 6.116 \\
\hline Mean (Ln(children+1)) & -0.263 & -4.572 & -0.330 & -4.206 & -0.452 & -6.662 & -0.575 & -4.673 \\
\hline Mean (Ln(adults)) & -0.206 & -3.855 & 0.003 & 0.052 & -0.268 & -3.991 & -0.148 & -1.341 \\
\hline$\sigma(\varepsilon)$ & 1.338 & & 0.966 & & 1.217 & & 1.250 & \\
\hline$\sigma(v)$ & 1.056 & & 0.711 & & 1.018 & & 0.830 & \\
\hline$\%$ of variance due to $v$ & $38.37 \%$ & & $35.12 \%$ & & $41.16 \%$ & & $30.61 \%$ & \\
\hline Number of Observations & 30356 & & 11256 & & 20510 & & 8501 & \\
\hline Log Likelihood & -56603 & & -21157 & & -39217.9 & & -16957 & \\
\hline Number of Individuals & 8130 & & 3191 & & 6361 & & 2690 & \\
\hline
\end{tabular}

\section{Income satisfaction inequality}

This section presents the concept of income satisfaction inequality $\left(I_{s a t}\right)$, which is derived by generalizing the objective income inequality concept. Let us assume two individuals $A$ and $B$ with incomes $y_{A}$ and $y_{B}$ and personal circumstances $X_{A}$ and $X_{B}$, respectively, where $X$ stands for the vector of all relevant variables except income.

Then the incomes $y_{A}$ and $y_{B}$ are equivalent satisfaction-wise, if

$$
I S^{*}\left(y_{A}, X_{A}\right)=I S^{*}\left(y_{B}, X_{B}\right)
$$


Or in words, incomes $\mathrm{y}_{\mathrm{A}}$ and $\mathrm{y}_{\mathrm{B}}$ are equivalent if individuals $\mathrm{A}$ and $\mathrm{B}$ are equally satisfied financially, given their different background circumstances $X$. The case $I S^{*}(y, X) \equiv \ln (y)$, where income satisfaction and objective income coincide, is a special case of the income satisfaction concept. This would be the case if all coefficients in Equation (2) would have been zero except the income coefficients. From Table 2, it is clear that other variables than income influence income satisfaction, i.e., populations with the same objective income distributions may have a different distribution of income satisfaction.

In contrast to what is sometimes thought most income inequality measures are based on a cardinal utility concept. The inequality index is defined as $I=I\left(f_{1}\left(y_{1}\right), \ldots, f_{N}\left(y_{N}\right)\right)$. It follows that the impacts of income increases for one individual are cardinally defined and the same holds for the comparison of income changes between individuals. We may change the functions $f_{1}\left(y_{1}\right), \ldots, f_{N}\left(y_{N}\right)$ into monotonic transforms $\tilde{f}_{1}\left(y_{1}\right), \ldots, \tilde{f}_{N}\left(y_{N}\right)$ but then the inequality index will be changed as well. We may think, for instance, on $f(y)=y$ and $\tilde{f}(y)=\ln (y)$. We may see $\tilde{f}=I S *$ as the specification in this paper.

In this paper, we consider $\operatorname{Var}\left(\operatorname{Ln}\left(I S^{*}\right)\right)=I_{\text {sat }}$ as our inequality measure. ${ }^{3}$ It is well known that the variance of log-incomes is not an ideal inequality measure, and this holds as well for the variance of income satisfactions, but the problem is that other measures also suffer from problems. There is no ideal measure. One evident advantage of the variance is its decomposability, which we shall use in this paper. As pointed out before, we may just as well take another statistic based on $\operatorname{Ln}\left(\operatorname{IS}{ }^{*}\right)$ like Theil's entropy, or the Atkinson index. Within the scope of this paper this would not add new information.

Table 3 presents estimates of the income satisfaction inequalities in the four sub-samples, which we compare with the corresponding objective income inequality. In the first line we present the objective income inequalities. In the second line we present the corresponding income satisfaction inequalities, defined as the variances of the structural parts of the estimated income satisfactions. In the third line we present

\footnotetext{
${ }^{3}$ The variance of $\operatorname{Ln}(I S)$ was calculated using individual weights as available in the GSOEP data. The weights represent the inverse probability of selection.
} 
the structural variance as a percentage of the 'total' variance, that is, the structural variance plus the error variance $\left(\sigma^{2}(v)+\sigma^{2}(\varepsilon)\right)$. For workers total variance is twenty times (!) the structural variance while for non-workers the proportion is ten to one. This is of course due to the small explanatory power of these models in terms of $R^{2}$ or pseudo- $R^{2}$. We may also interpret this result as saying that by far the largest part of satisfaction inequality is caused by unobserved heterogeneity and/or random errors. As far as it is caused by random disturbances we cannot improve on this result. As far as it is caused by unobserved variables we have to look after additional relevant observable individual characteristics. Both objective income and structural satisfaction inequalities seem to underestimate the perceived inequality. We have to accept this as a fact of life. It does not imply that the structural inequalities have become devoid of interest.

Table 3: Objective and income satisfaction inequalities

\begin{tabular}{lcccc}
\hline & West Workers & East Workers & $\begin{array}{c}\text { West-Non } \\
\text { Workers }\end{array}$ & $\begin{array}{c}\text { East-Non } \\
\text { Workers }\end{array}$ \\
\hline Variance of objective Log-incomes & 0.218 & 0.173 & 0.284 & 0.218 \\
$\begin{array}{l}\text { Variance of Log-income satisfactions } \\
\text { (structural part) }\end{array}$ & 0.186 & 0.141 & 0.357 & 0.328 \\
$\begin{array}{l}\text { structural part as percentage of total } \\
\text { variance }\end{array}$ & $6.03 \%$ & $8.94 \%$ & $12.41 \%$ & $12.70 \%$ \\
$\begin{array}{l}\text { Total satisfaction variance } \\
\text { Number of Observations }\end{array}$ & 3.08 & 1.57 & 2.87 & 2.58 \\
\hline
\end{tabular}

Table 3 shows that objective income inequality is larger in the West than in the East, both for workers and for non-workers. We also see that income inequality is larger within the group of non-workers than for workers. For workers the structural satisfaction inequality is smaller than that with respect to objective incomes, while the opposite holds for non-workers. For instance, for western non-workers the objective inequality is 0.284 and the subjective analogue is 0.357 .

Next, we present an income satisfaction inequality decomposition to identify the contribution of each observable variable $X$ and $Z$ to income satisfaction inequality. Since the income satisfaction inequality is here defined in terms of variance, studying the causes of this inequality is equivalent to decomposing the variance of the income satisfaction. The prototype of a decomposition is based on the model 


$$
\ln (Z)=\ln \left(Z_{1}\right)+\ldots+\ln \left(Z_{k}\right)
$$

where we assume that the components are uncorrelated, i.e., $\operatorname{cov}\left(Z_{i}, Z_{j}\right)=0$. We get

$$
\sigma_{Z}^{2}=\sigma_{Z_{1}}^{2}+\ldots+\sigma_{Z_{k}}^{2}
$$

Hence, we may assign to each component its relative share in contributing to the overall variance/inequality. The shares are

$$
p_{i}=\frac{\sigma_{Z_{i}}^{2}}{\sigma_{Z}{ }^{2}}
$$

The shares add up to one and each share is non-negative. Unfortunately, this decomposition is impossible if the components are correlated, i.e., $\operatorname{cov}\left(Z_{i}, Z_{j}\right) \neq 0$. This is obviously the case for the $I S$ - equation as age, income, education and children are correlated. Therefore, we have to apply a second-best solution.

The variance decomposition we apply is performed by the well-known stepwise regression procedure. ${ }^{4}$ We notice that we defined the structural part of equation (2) as the right-hand side without error-terms. We denote it by $I S^{(s)}$ for short. Its variance is just the structural satisfaction inequality. If we regress $I S^{(s)}$ on all variables in (2) simultaneously we get of course an $R^{2}$ of $100 \%$. If we regress $I S^{(s)}$ on one variable $X_{1}$ (and a constant) we get an $R_{1}^{2}$ of less than $100 \%$. It may be interpreted as the contribution of $X_{1}$ to total inequality. Adding a second variable $X_{2}$ the $R_{2}^{2}$ is increased from $R_{1}^{2}$ to $R_{2}^{2}$. The difference $\left(R^{2}{ }_{2}-R_{1}{ }_{1}\right)$ may be interpreted as the additional inequality contribution caused by differences in the variable $X_{2}$. It is obvious that this decomposition depends on the order of introduction of the variables except in the unlikely case that the two variables $X_{1}$ and $X_{2}$ are non-correlated. This variance decomposition method may be generalized to any arbitrary number of variables. The usual option in standard-software is that the order of successive introduction of the

\footnotetext{
${ }^{4}$ An alternative decomposition would be by means of principal components. However, here we have the disadvantage that it is often difficult to understand what these principal components stand for.
} 
variables is chosen, such that at each step the incremental explanation is maximized. We call this order the maximizing order. Obviously, we may impose any other order as well. In Table 4.a we present for each of the four sub-samples the inequality decomposition according to the (sample-specific) maximizing order. For Western workers we find that a very large part may be explained by the long-term variables. The variable Mean ( $\operatorname{Ln}($ net family income), that is the average log-net family income over the period 1992-1997 explains $65.63 \%$ of the structural inequality. The next factor Mean ( $\operatorname{Ln}($ adults)) gives an additional contribution of $12.21 \%$ and a similar contribution is given by the number of children (defined as living at home below 16). The remaining transitional components give only a minor contribution adding up to about $12 \%$. For Western non-workers the picture is somewhat similar, although the long-term contribution is smaller. One transitional factor Ln(age) plays a significant role as well. For the Eastern part of the population the situation is completely different. Here the long-term elements play a negligible role, while the transitional factors are leading. This is in conformity with the rather stormy developments in EastGermany when compared to those in the western part of the country.

Table 4a. Variance decomposition of income satisfaction inequality according to maximizing order. In percentages.

\begin{tabular}{lcccc}
\hline Variable & West Workers & East Workers & $\begin{array}{c}\text { West } \\
\text { Non-Workers }\end{array}$ & $\begin{array}{c}\text { East } \\
\text { Non-Workers }\end{array}$ \\
\hline & & & & \\
Ln2(age) & $2.59 \%$ & $1.30 \%$ & $2.62 \%$ & $1.62 \%$ \\
Ln(age) & $3.40 \%$ & $11.54 \%$ & $14.97 \%$ & $22.03 \%$ \\
Ln(net family inc.) & $0.87 \%$ & $56.69 \%$ & $0.86 \%$ & $26.43 \%$ \\
Male & $0.17 \%$ & $1.05 \%$ & $3.48 \%$ & $1.14 \%$ \\
Living together? & $2.07 \%$ & $1.75 \%$ & $3.06 \%$ & $2.42 \%$ \\
Ln(years Education) & $1.17 \%$ & $0.01 \%$ & $0.76 \%$ & $8.68 \%$ \\
ln(net fam.inc.) & $0.15 \%$ & $0.00 \%$ & $0.56 \%$ & $0.00 \%$ \\
& & & & \\
Ln(adults) & $1.26 \%$ & $11.44 \%$ & $0.12 \%$ & $22.17 \%$ \\
Ln(Child.+1) & $0.17 \%$ & $8.16 \%$ & $0.08 \%$ & $13.95 \%$ \\
Earner & $0.05 \%$ & $0.59 \%$ & XXX & XXX \\
& & & & \\
Mean(Ln(net fam. Inc.)) & $65.63 \%$ & $6.06 \%$ & $35.13 \%$ & $0.62 \%$ \\
Mean(Ln(Child.+1)) & $10.25 \%$ & $0.01 \%$ & $21.73 \%$ & $0.26 \%$ \\
Mean(ln(adults)) & $12.21 \%$ & $1.41 \%$ & $16.62 \%$ & $0.69 \%$ \\
\hline
\end{tabular}

In Table 4.b we present the corresponding decompositions, where we fix the order for each sample as the order of variables in Table 2. 
Table 4b. Variance decomposition of income satisfaction inequality according to order in Table 2. In percentages.

\begin{tabular}{lcccc}
\hline & $\begin{array}{c}\text { West } \\
\text { Workers }\end{array}$ & East Workers & $\begin{array}{c}\text { West } \\
\text { Non-Workers }\end{array}$ & $\begin{array}{c}\text { East } \\
\text { Non-Workers }\end{array}$ \\
\cline { 1 - 3 } Ln(age) & & & & \\
Ln2(age) & $0.12 \%$ & $5.68 \%$ & $9.18 \%$ & $2.72 \%$ \\
Ln(net family inc.) & $1.34 \%$ & $1.77 \%$ & $23.41 \%$ & $50.06 \%$ \\
Ln(years Education) & $56.60 \%$ & $61.55 \%$ & $42.99 \%$ & $29.68 \%$ \\
Ln(adults) & $6.48 \%$ & $1.32 \%$ & $1.43 \%$ & $0.68 \%$ \\
Ln(Child.+1) & $10.32 \%$ & $14.20 \%$ & $5.75 \%$ & $11.98 \%$ \\
ln(net fam.inc.) & $4.77 \%$ & $4.83 \%$ & $2.51 \%$ & $1.94 \%$ \\
Male & $0.18 \%$ & $0.02 \%$ & $0.09 \%$ & $0.00 \%$ \\
Living together? & & & & \\
Earner & $0.28 \%$ & $1.12 \%$ & $3.88 \%$ & $1.00 \%$ \\
& $3.41 \%$ & $2.06 \%$ & $3.63 \%$ & $0.38 \%$ \\
Mean(Ln(net fam. Inc.)) & $13.12 \%$ & $5.14 \%$ & $5.05 \%$ & $0.00 \%$ \\
Mean(Ln(Child.+1)) & $0.48 \%$ & $1.37 \%$ & $0.23 \%$ & $0.68 \%$ \\
Mean(ln(adults)) & $2.68 \%$ & $0.01 \%$ & $1.85 \%$ & $0.25 \%$ \\
\hline
\end{tabular}

When we compare Tables $4 \mathrm{a}$. and $4 \mathrm{~b}$., we find that the order in which the different variables are brought into play is very important. Actually, the main burden of the inequality shifts in Table $4 \mathrm{~b}$. to the transitory factors, although the explanation of the long-term factors being about $16 \%$ is still larger than the $12 \%$ given to the transitory factors in Table 4a. For non-workers we find that age becomes a very important factor determining inequality.

Finally, we may take a look at income satisfaction inequality in the whole of Germany $(\mathrm{G})$. We use the well-known variance decomposition formula, where total variance is split up into the sum of the two within-group-variances and the betweengroups variance. The two groups are the West-and East-German population in this case. More precisely we have the identity

$$
I_{\text {sat }}(G)=p_{w} I_{\text {sat }}(W)+p_{E} I_{\text {sat }}(E)+I_{\text {sat }}(\text { BetweenEand } W)
$$

where the $p$ 's stand for the relative population shares. The last term is calculated by taking the variance of the mean of Western log-income satisfaction and the mean of Eastern log-income satisfaction with respect to the overall mean log-income satisfaction. In a similar way we may go on and decompose $I_{s a t}(W)$ and $I_{\text {sat }}(E)$ with 
respect to workers and non-workers. That decomposition is tabulated in Table 5. The results are comparable to those presented in Table 3.

Table 5. Between-group decompositions for Income Satisfaction Inequality $\left(I_{s a t}\right)$

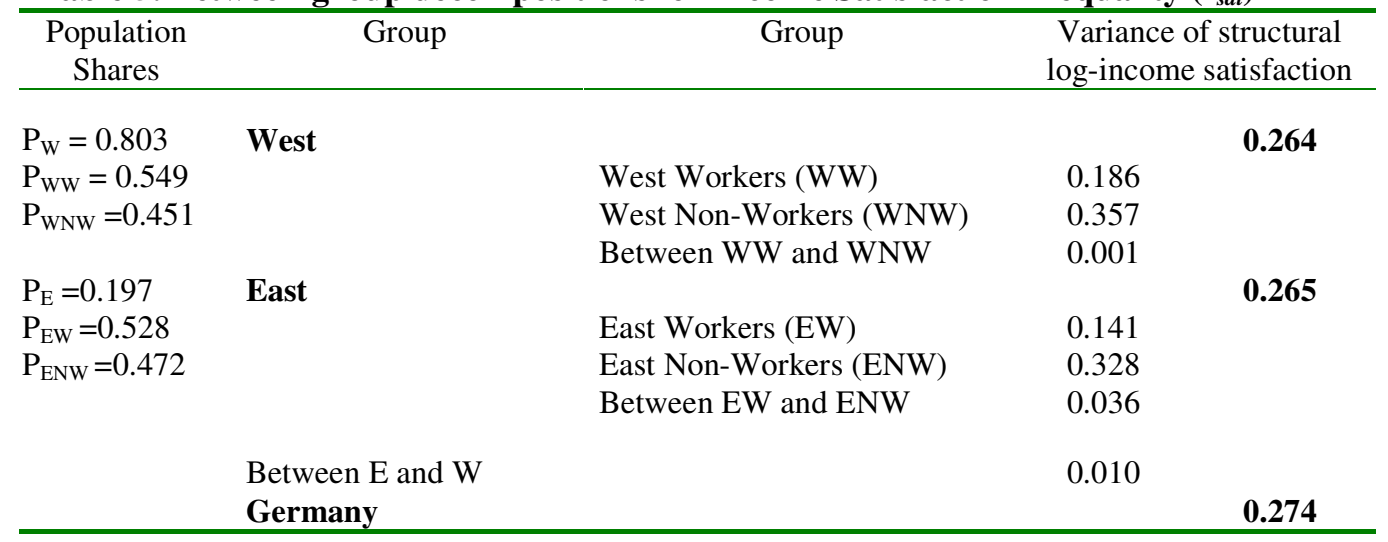

Table 5 shows that the income satisfaction inequality in Germany as a whole is 0.274 , and that there is virtually no difference between the two inequalities in East and West. The income satisfaction distribution of Non-workers is more unequal than for workers in both parts of the country.

The same exercise may be done for the objective income inequality. The results are presented in Table 6. Again, the reader can compare these results with the ones presented at Table 5. Table 6 illustrates that the objective income inequality in Germany as a whole is 0.259 , which is somewhat smaller than the income satisfaction inequality. The Westerners suffer from a larger inequality than in the East and the same holds for the corresponding subgroups of workers and non-workers..

Table 6. Between group decompositions for Income Inequality

\begin{tabular}{|c|c|c|c|c|}
\hline $\begin{array}{c}\text { Population } \\
\text { Shares }\end{array}$ & Group & Group & \multicolumn{2}{|c|}{$\begin{array}{c}\text { Variance of objective } \\
\text { Log-incomes }\end{array}$} \\
\hline $\begin{array}{l}P_{W}=0.803 \\
P_{W W}=0.549 \\
P_{W N W}=0.451 \\
P_{E}=0.197 \\
P_{E W}=0.528 \\
P_{E N W}=0.472\end{array}$ & West & $\begin{array}{l}\text { West Workers } \\
\text { West Non-Workers } \\
\text { Between WW and WNW } \\
\text { East Workers } \\
\text { East Non-Workers } \\
\text { Between EW and ENW }\end{array}$ & $\begin{array}{c}0.218 \\
0.284 \\
0.0132 \\
\\
0.173 \\
0.218 \\
0.0248\end{array}$ & 0.261 \\
\hline & $\begin{array}{l}\text { Between } \mathrm{E} \text { and } \mathrm{W} \\
\text { Germany }\end{array}$ & & 0.0063 & 0.259 \\
\hline
\end{tabular}


Recently Gary Fields (2002) suggested another decomposition, which may be succinctly described as follows. If there holds $Z=\beta_{1} Z_{1}+\ldots+\beta_{k} Z_{k}+\varepsilon$, there also holds

$$
\operatorname{var}(Z)=\beta_{1} \operatorname{cov}\left(Z_{1}, Z\right)+\ldots+\beta_{k} \operatorname{cov}\left(Z_{k}, Z\right)+\operatorname{var}(\varepsilon, Z)
$$

Division by $\operatorname{var}(Z)$ yields

$$
p_{1}+\ldots+p_{k}+p_{\varepsilon}=1
$$

This is another way to define inequality or variance shares. The advantage of this decomposition is that the shares do not depend on the order of introduction of the variables. They are uniquely defined, thereby avoiding the element of arbitrariness, which is inherent to the stepwise procedure, followed above. However, the price to be paid is that the shares $p$ may be negative or larger than one, which makes interpretation cumbersome. It is therefore, that we did not use the Fieldsdecomposition.

\section{Conclusions}

In this paper we extended the objective income concept by defining the subjective income satisfaction concept. Similarly we extend the objective income inequality concept by defining an income satisfaction inequality concept. The $I_{\text {sat }}$ measure differs from objective measures of inequality as individual subjective satisfaction with income is used instead of objective income. In other words, the paper presents estimates for feelings of income inequality. The measure $I_{\text {sat }}$ includes objective income inequality as a special case, namely, when subjective income satisfaction and income are identical.

We find that only a relatively small part of $I_{\text {sat }}$ can be attributed to observed factors. This does not necessarily imply that there would be no other observable causes of inequality. It may be that the specification presented in Table 2 omitted relevant observable variables. Nevertheless, this is not very likely, given the large range of variables available in the GSOEP and the extensive research we did trying 
different possible specifications. Even if the variance due to observable factors is rather small, it is interesting to look at it, given that the objective variables are the only ones, which policy makers can take into account. The role of income in explaining income satisfaction inequality is not insignificant but it is not the only causing factor. The number of people in the household and the age distribution are important as well. Thus, even if objective income inequality remains certainly an important statistic to monitor the societal distribution process, this exercise shows that psychological feelings of inequality are relevant as well. Evidently, this research should be repeated for other populations, before we may generalize the findings of this paper.

This paper contributes to the literature of inequality by presenting an income satisfaction concept, which can be compared to objective measures of inequality. Income satisfaction inequality differs from the established measures of inequality by using individual perceptions as a basis to make incomes comparable. The traditional measures of inequality introduce subjectivism via intuition by, for example, imposing family equivalence scales (such as the Oxford/OECD scale) or by introspection in choosing a concrete welfare function specification with a numerically determined risk/inequality aversion parameter (Atkinson, 1970). The introduction of income satisfaction does not imply that objective measurement should be replaced by subjective concepts throughout, but only that both measures have a different role to play. The subjective concept is in our opinion a valuable addition to the family of inequality measures. 


\section{References}

Aitchison, J. and J.A.C. Brown, 1960. The Lognormal Distribution. Cambridge University Press, London.

Argyle, M., 1999. Causes and correlates of happiness. In: D. Kahneman, E. Diener and N. Schwarz (eds.). Well-Being: The Foundations of Hedonic Psychology. Russell Sage Foundation, New York. Chapter 18.

Atkinson, A.B., 1970. On the measurement of inequality. Journal of Economic Theory, 2: 244-263.

Atkinson, A.B. and F. Bourguignon (eds), 1999. Handbook of Income Distribution, North Holland, Amsterdam.

Baker, M., 1997. Growth-rate heterogeneity and the covariance structure of life-cycle earnings. Journal of Labor Economics, 15:338-375.

Brickman, P. and D.T. Campbell, 1971. Hedonic relativism and planning the good society. In: M.H. Apley (ed.). Adaptation-level theory: A symposium. Academic Press, New York. Pages: 287-302.

Cantril, H., 1965. The pattern of human concerns. Rutgers University Press. New Brunswick.

Clark, A. E. and A.J. Oswald, 1994. Unhappiness and unemployment. Economic Journal, 104: 648-659.

Clark, A. E. and A.J. Oswald,1996. Satisfaction and comparison income. Journal of Public Economics, 61: 359-381.

Cowell, F.A., 1999. Measurement of Inequality in Atkinson, A.B. and F. Bourguignon (eds), 1999. Handbook of Income Distribution, North Holland, Amsterdam.

Dalton, H., 1920. The Measurement of the Inequality of Incomes. Economic Journal, 30: $348-361$.

Dickens, R. (2000). The evolution of individual male wages in great-Britain:19751995. The Economic Journal,110: 27-49.

Diener, E. and R.E. Lucas, 1999. Personality and subjective well-being. In: D. Kahneman, E. Diener and N. Schwarz (eds.). Well-Being: The Foundations of Hedonic Psychology. Russell Sage Foundation, New York. Chapter 11.

Diener, E., E.M Suh, R.E. Lucas and H.L. Smith, 1999. Subjective well-being: Three decades of progress. Psychological Bulletin, 125: 276-302. 
Di Tella, R., R.J. MacCulloch and A.J. Oswald, 2001. Preferences over Inflation and Unemployment: Evidence from Surveys of Happiness. American Economic Review, 91: 335-341.

Easterlin, R.A., 2000. The worldwide standard of living since 1800. The Journal of Economic Perspectives, 14: 7-26.

Ferrer-i-Carbonell, A. and B.M.S. Van Praag, 2001. The subjective costs of health losses due to chronic diseases. An alternative model for monetary appraisal. Health Economics, 11: 709-722.

Ferrer-i-Carbonell, A., 2002. Income and Well-being: An Empirical Analysis of the Comparison Income Effect, Tinbergen Institute Working Paper 2002-019.

Fields, G.S., 2002. Accounting for Income Inequality and Its Change: A New Method, with Application to the Distribution of Earnings in the United States, forthcoming in Research in Labor economics.

Friedman, M., 1957. A theory of the consumption function. Princeton University Press, Princeton, NJ.

Frey, B.S. and A. Stutzer, 2000. Happiness, economy and institutions. Economic Journal, 110: 918-938.

Frijters, P., 2000. Do individuals try to maximize general satisfaction? Journal of Economic Psychology, 21: 281-304.

Gini, C., 1912. Variabilita e Mutabilita, Bologna, Italy.

Helson, H., 1964. Adaptation level as frame of reference for prediction of psychological data. The American Journal of Psychology, 60: 1-29.

Hunt, J., 1999. Determinants of non-employment and unemployment durations in East Germany. NBER Working Paper Series No. 7128, Cambridge MA.

Hunt, J., 2000. Why do people still live in East? The Institute for the Study of Labor (IZA) Discussion Paper No. 123, Bonn, Germany.

Kahneman, D., E. Diener and N. Schwarz (eds.), 1999. Foundations of Hedonic Psychology: Scientific Perspectives on Enjoyment and Suffering. Russel Sage Foundation, NY.

Kapteyn, A. and F.G. Van Herwaarden, 1980. Independent welfare functions and optimal income distribution. Journal of Public Economics, 14: 375-397.

Likert, R., 1932. A technique for the measurement of attitudes. Archives of Psychology, 140:55. 
Lillard, L. and R. Willis, 1978.. Dynamic aspects of earnings mobility. Econometrica, 46: 985-1012.

Mundlak, Y., 1978. On the Pooling of Time Series and Cross Section Data. Econometrica, 46: 69-85.

Ng, Y-K., 1997. A Case for Happiness, cardinalism, and interpersonal comparability. The Economic Journal, 107: 1848-1858.

Pannenberg, M., 1997. Documentation of Sample Sizes and Panel Attrition in the German Socio Economic Panel (GSOEP). Discussion Paper No. 150, Deutsches Institut für Wirtschaftsforschung, Berlin.

Plug, E., B. van Praag, P. Krause, and G, Wagner, 1997. Measurement of poverty: Exemplified by the German case. In: N. Ott and G.G. Wagner (ed), Income inequality and poverty in Eastern and Western Europe. Physica-Verlag, Heidelberg. Pp. 69-89.

Rao, C.R., 1973. Linear Statistical Inference and its Applications, Wiley \& Sons, New York.

Sen, A.K., 1973. On economic inequality. Reprinted 1997. Clarendon Press, Oxford.

Sen, A.K., 1999. The possibility of social choice. American Economic Review, 89: 349-378.

Silber, J. (ed.). 1999. Handbook of income inequality measurement. Kluwer Academic: Dordrecht, the Netherlands.

Theil, H., 1967. Economics and Information Theory, North-Holland Publishing Cy., Amsterdam.

Theil, H., 1979. The measurement of inequality by components of income. Economics Letters, 2: 197-199.

Van Praag, B.M.S., 1971. The welfare function of income in Belgium: an empirical investigation. European Economic Review, 2: 337-369.

Van Praag, B.M.S., 1978.The Perception of Income Inequality. In: W. Krelle and A.F. Shorrocks (eds.). Personal Income Distribution. North-Holland Publishing Company, Amsterdam. Pages: 113-136.

Van Praag, B.M.S., 1991. Ordinal and cardinal utility: an integration of the two dimensions of the welfare concept. Journal of Econometrics, 50: 69-89.

Van Praag, B.M.S., P. Frijters, and A. Ferrer-i-Carbonell, 2003. The anatomy of wellbeing. Journal of Economic Behavior and Organization, 51: 29-49. 
Wagner, G.G., Burkhauser, R.V., Behringer, F., 1993. The English language public use file of the German Socio-Economic Panel. Journal of Human Resources, 28: 429-433. 